\section{The increase in spend}

Clare Gerada offers no response to the problem of increasing spend on health at a time of diminishing funding whether due to political or economic circumstances. We have to face up to this before more and more of our gross domestic product feeds an increasingly medicalised, secondary care-based system.

I am deeply involved in the clinical commissioning group (CCG) in Sheffield but that does not mean I agree with the reforms; we have no choice but to make the best of this and resist the pressure to marketise for the sake of it. We are developing deeper levels of joint working and understanding with our teaching hospital trusts than we have for years, with a radical reform of urgent and non-urgent care in development.

Of course there is pressure on the soft target of elective referrals while we learn how to free up resources from cost-effective alternatives to non-elective hospital admissions. Audits have shown a generic waste of resources through poor quality referrals; we have to address this directly, as reliance on professional behaviour is not going to work. We have been building an awareness of cost as a consequence of GP behaviour through practice-based commissioning. However, we can learn to look at cost as organisations, whether practices, federations, or CCGs; it is patronising to GPs if cost is only ever translated as something that enters the consultation.

We are reaching a point where GPs are starting to take part in the potential positive outcomes of joint work. I don't recognise much about the scenarios Clare uses as outcomes of this bill, and am concerned that this message will neither encourage engagement that gets the best out of bad legislation nor result in a mass protest; instead we will all have ourselves to blame for keeping our heads in the sand.

If on the other hand Lansley has played a magnificent sleight of hand, I have a substantial hat to eat.

\section{Charles Heatley,}

GP, Birley Health Centre, Chair, Hallam and South Consortium, 120 Birley Lane, Sheffield, S12 3BP.

E-mail: charles.heatleylanhs.net

\section{Ubi Scientia in the midst of the cosy cardigans of Caritas}

Checkland's letter raises important concerns about barriers to engagement between academic and 'applied' primary care settings. ${ }^{1}$ Academic primary care is a distinct scientific discipline working within, and alongside, primary care to support and challenge practice through scholarly activity. Issues related to scientific rigour and trustworthiness of scholarly activity, along with the evaluative validity/utility and coherence of ideas are of importance in both the academic and applied settings. Identifying how best to integrate these two perspectives highlights a key challenge to engagement; in thinking about how we communicate ideas about, and the results of, academic practice and scholarly activity. These are issues that the Society for Academic Primary Care (SAPC) is actively debating and addressing and are reflected in our revised position statement. ${ }^{2}$

The 2012 SAPC conference will be held jointly with the Royal College of General Practitioners, bringing academic and applied practice together in one meeting. We are revising the abstract submission process to require an explicit description of the utility and significance of the submitted work for primary care practice and policy. We are programming workshops that address the utility of sociological scholarly activity in the consultation room and the latest evidence-base on commissioning. And we will be introducing a new festival of dangerous ideas, ${ }^{3}$ the use of scholarly activity to challenge, spark news ideas, and identify and promote change.

We will be posting plans for 2012 on our website as they emerge. We welcome comments on these ideas. And invite everyone, including Dr Checkland, to join us at the 2012 meeting. ${ }^{4}$

\section{Joanne Reeve,}

SAPC Communications Officer; NIHR Clinician Scientist in Primary Care, University of Liverpool, B122 Waterhouse Buildings, 1-5 Brownlow Street, Liverpool, L69 3GL.

E-mail: Joanne.Reevediliverpool.ac.uk

Helen Lester,

Chair of SAPC and 2012 Conference Chair;
Professor of Primary Care, University of Birmingham Primary Care Clinical Sciences Building, Birmingham.

\section{REFERENCES}

1. Checkland K. Ubi Scientia in the midst of the cost cardigans of Caritas? Br J Gen Pract 2011; 61(591): 608.

2. Society for Academic Primary Care. SAPC position statement. Oxford: SAPC, 2011. http://www.sapc.ac.uk/index.php/positionstatement laccessed 8 Nov 2011).

3. Reeve J, Abholz H, Bailey T, et al. A pause for thought: reflections on the 2011 SAPC conference. Prim Health Care Res Dev 2011; 12: 393-394.

4. Society for Academic Primary Care. Conference 2012. Oxford: SAPC, 2011.

http://www.sapc.ac.uk/index.php/conference2012 laccessed 8 Nov 2011).

DOI: 10.3399/bjgp11X612981

\section{The QOF, NICE, and depression}

In his defence of the depression parts of the QOF, Alan Cohen also unwittingly illustrates some of the problems of the whole process. For instance, when he states that patients like the use of questionnaires, it is because they feel as though their symptoms are being taken seriously', not because he can quote more substantive evidence that it makes a difference to harder outcomes. Too much concentration on process and not outcomes. Note that $\mathrm{Dr}$ Cohen is not claiming GPs are taking the symptoms more seriously; the implication is that the designers of the QOF would favour the quick, somewhat superficial, and very impersonal patient health questionnaire (PHQ) over serious engagement between GPs and their patients' personal concerns. Not only de-professionalising, as Toop pointed out in his editorial, ${ }^{2}$ but very destructively reducing all patients from individuals with their own contexts and concerns to units in a production line.

Then there is the encouragement to overreliance on the $\mathrm{PHQ}$. This has been consistently shown to overestimate severe depression when compared with other measures. The widespread and uncritical use of the $P H Q$ may be leading to overdiagnosis of depression with excessive antidepressant prescribing. Those responsible for the workings of the QOF need to be reminded constantly that all medical interventions capable of doing good 
can also do harm.

However, it is the statement that "Not to have incentivised GPs to identify a group of people who were more at risk clinically .. would have been negligent' that is truly outrageous. Here there are QOF points for applying a universal method that also has substantial error rates, with the possibility again that this will lead to over and under identification. Dr Cohen here has subscribed to the suggestion both damaging and now proved to be erroneous, that GPs will only take action that is financially rewarded. If the lie were correct, then what is the implication for all those other patients with long-term disabling conditions, also at higher risk of depression? Or is he suggesting that this QOF provision should be extended to all patients? In which case it would become, effectively, a screening programme for which, again as Toop points out, there is no convincing evidence. ${ }^{2}$

The QOF approach began as a limited set of targets to encourage more universal application of a number of measures that were backed by sound evidence and generally accepted as both achievable and beneficial. It has gradually expanded to incorporate more dubious measures that command less acceptance, and looks more and more like a set of hoops to make recalcitrant GPs work harder with little extra gain for patients. Meanwhile, the clamour from numerous lobby groups for inclusion of their pet measures in the QOF continues to grow. Not only de-professionalising, but very depressing and sadly, all too predictable.

David Jewell,

20 Duchess Road, Bristol, BS8 2LA.

E-mail: david.jewell661agooglemail.com

\section{REFERENCES}

1. Cohen A. The QOF, NICE and depression. $\mathrm{Br} J$ Gen Pract 2011; 61(590): 549

2. Toop L. The QOF, NICE and depression: a clumsy mechanism that undermines clinical judgement. Br J Gen Pract 2011; 61(588): 432-433.

\section{Primary care electronic health records: who is in control?}

As a late adopter of electronic health records, apart from repeat prescribing, I was reluctant to leave my efficient paper practice notes that I controlled and wrote my patient's narrative. It is now routine to record such contacts on the computer record but my eyes rarely lift from the keyboard. At the same time part of my mind is involved with the software set-tasks, often government driven, that need to be slavishly tackled in order to gain essential payment. I warned my past colleagues that this was the electronic hamster wheel of the medical primary care workload and they have nearly all retired early. I am still at the primary care coalface but this is due in part in trying to wrest some personal control of this electronic record in order to aid my patient care.

Here I refer to the recommendation to use clinical indications on all repeat prescriptions, which is a an excellent use of the repeat prescription electronic process, described in detail on my website.' The latest draft of the GMC guidelines on good prescribing recommends that all doctors should consider including such a process in their prescribing. ${ }^{2}$ Smoking recording is another area that has needed revisiting and my smoking pack year calculator ${ }^{3}$ provides a smoking exposure dose on those ever smokers' so that smoking is searchable and potentially predictive. In addition I have developed some paediatric drug dosage calculators to aid my busy everyday work. These self-created additions have given me the much needed personal 'locus of control' of the electronic health record, but will scream in the face of industry standard setting and may make it impossible to transfer my detailed data reliably from GP system to system. Still I cherish my patient's records in our small practice and a recent letter from a young consultant vascular surgeon unprompted said it all ... 'The computerised notes summary in your surgery is extremely impressive'.

\section{Nigel Masters,}

GP, Highfield Surgery, Highfield Way, Hazlemere, Buckinghamshire, HP15 7UW. E-mail: nigel.mastersanhs.net

\section{REFERENCES}

1. Masters N. Learn about clinical indications. www.http://clinicalindications.com/about/ (accessed 8 Nov 2011).

2. General Medical Council. Good practice in prescribing and managing medicines and devices consultation document on prescribing for doctors June 2010. London: GMC, 2010.

3. Masters N, Tutt C. Smoking pack years. http://www.smokingpackyears.com laccessed 8 Nov 2011).

\section{Electronic health records: research into design and implementation}

I was surprised that the only systematic review referenced in the editorial on electronic records in your October issue ${ }^{1}$ was 10 years old and based on studies of record systems that are long obsolete. ${ }^{2}$ The editorial failed to mention a 2009 systematic review by my own team, that summarised 24 previous systematic reviews on electronic records lincluding Mitchell and Sullivan's) and that offered a new synthesis of primary literature from the organisation and management literature, including but not limited to actor-network theory approaches. ${ }^{3}$ The editorial also failed to mention the 2011 'review of reviews' of ehealth applications by Ashly Black and colleagues, that summarised 108 previous systematic reviews on electronic records and other information and communication technologies in health care. ${ }^{4}$ While this editorial made some good points and referenced some of the important recent studies and commentaries in this area, it was 'freely submitted, not externally peer reviewed' and illustrates the dangers of such a policy.

\section{Trisha Greenhalgh,}

Professor of Primary Health Care and Director, Centre for Primary Care and Public Health, Blizard Institute, Barts and The London School of Medicine and Dentistry, 58 Turner Street, London, E1 2AB. E-mail: p.greenhalghaqmul.ac.uk

\section{REFERENCES}

1. Beasley JW, Holden RJ, Sullivan F. Electronic health records: research into design and implementation. Br J Gen Pract 2011; 61(591): 604-605.

2. Mitchell E, Sullivan F. A descriptive feast but an evaluative famine: systematic review of published articles on primary care computing during 1980-1997. BMJ 2001; 322(7281): 279-282.

3. Greenhalgh T, Potts H, Wong G, et al. Tensions and paradoxes in electronic patient record research: a systematic literature review using the metanarrative method. Milbank Q 2009; 87(4): 729-788.

4. Black AD, Car J, Pagliari $C$, et al. The impact of eHealth on the quality and safety of health care: a systematic overview. PLoS Med 2011; 8(1): e1000387. 